\title{
Gestión de residuos y transferencia de vulnerabilidad en Lima/Callao
}

Gestion des déchets et transfert de vulnérabilité à Lima/Callao

Waste management and vulnerability transfer in Lima/Callao

\section{Mathieu Durand y Pascale Metzger}

\section{(2penEdition}

Journals

Edición electrónica

URL: http://journals.openedition.org/bifea/2396

DOI: 10.4000/bifea.2396

ISSN: 2076-5827

\section{Editor}

Institut Français d'Études Andines

Edición impresa

Fecha de publicación: 1 diciembre 2009

Paginación: 623-646

ISSN: 0303-7495

Referencia electrónica

Mathieu Durand y Pascale Metzger, " Gestión de residuos y transferencia de vulnerabilidad en Lima/ Callao », Bulletin de l'Institut français d'études andines [En línea], 38 (3) | 2009, Publicado el 01 junio 2010, consultado el 17 noviembre 2020. URL : http://journals.openedition.org/bifea/2396 ; DOI : https://doi.org/10.4000/bifea.2396

Les contenus du Bulletin de l'Institut français d'études andines sont mis à disposition selon les termes de la licence Creative Commons Attribution - Pas d'Utilisation Commerciale - Pas de Modification 4.0 International. 


\title{
Gestión de residuos y transferencia de vulnerabilidad en Lima/Callao
}

\author{
Mathieu Durand* \\ Pascale Metzger**
}

\begin{abstract}
Resumen
En la aglomeración de Lima/Callao la colecta y la eliminación de residuos sólidos se hacen difíciles por la ausencia de una autoridad que tenga competencia en todo el ciclo de la basura y en todo el territorio urbano. Los residuos producen riesgos principalmente sanitarios y ambientales. Analizar la gestión de residuos desde el enfoque de la vulnerabilidad permite evidenciar la producción de espacios operada por la gestión de los residuos, así como las lógicas espaciales de transferencia de residuos, y por ende de transferencia de vulnerabilidad, entre territorios y entre población. Estas transferencias de vulnerabilidad son indicadores de desigualdades ecológicas. Por lo tanto, las poblaciones más pobres, a pesar de desempeñar una función primordial en la eliminación de los residuos a través de su actividad de reciclaje, son las más expuestas a los riesgos producidos por estos residuos. En consecuencia, la disminución de la vulnerabilidad del sistema de gestión de residuos se hace a través de la concentración de la vulnerabilidad de territorios y de poblaciones muy localizados.
\end{abstract}

Palabras clave: residuos, transferencia de vulnerabilidad, desigualdades socioambientales, Lima

\section{Gestion des déchets et transfert de vulnérabilité à Lima/Callao}

\section{Résumé}

Dans I'agglomération de Lima/Callao, la collecte et l'élimination des déchets sont rendus difficiles par l'absence d'une autorité gestionnaire sur l'ensemble du cycle et sur tout le territoire urbain. Les déchets produisent des risques principalement sanitaires et environnementaux. Analyser la gestion des déchets sous l'angle de la vulnérabilité permet de mettre en évidence la production d'espaces opérée

* Université de Rennes 2, Centre de Recherche Espace et Société (UMR ESO 6590 CNRS), Institut Français d'Études Andines (IFEA, UMIFRE 17, CNRS-MAEE), casilla 18-1217, Lima 18, Perú. E-mail: m3durand@yahoo.fr

** Institut de Recherche pour le Développement (IRD), UR 029, programa Pacivur, Calle Teruel 357, Miraflores, casilla 18-1209, Lima 18,Perú. E-mail: pascale.metzger@ird.fr 
par la gestion des déchets, ainsi que des logiques spatiales de transfert de déchets, et donc de transfert de vulnérabilité, entre territoires et entre population. Ces transferts de vulnérabilité sont des marqueurs d'inégalités écologiques. Ainsi, les populations les plus pauvres, qui jouent une fonction primordiale dans l'élimination des déchets par leur activité de recyclage, sont les plus exposées aux risques produits par ces déchets. La diminution de la vulnérabilité du système de gestion des déchets se fait donc au travers de la concentration de la vulnérabilité de territoires et de populations très localisés.

Mots clés : déchets, transfert de vulnérabilités, inégalités socio-environnementales, Lima

\title{
Waste management and vulnerability transfer in Lima/Callao
}

\begin{abstract}
In the metropolitan area of Lima/Callao, the collection and elimination of waste are made difficult by the absence of an urban territory authority. Wastes produce health and environmental risks. Analysis of waste management from the perspective of vulnerability, allows observing the production of spaces by the waste management, as well as of spatial logic of waste transfer, and thus vulnerability transfer, between territories and between populations. These transfers of vulnerability are markers of ecological inequalities. Thus, the poorest people who are very important in the elimination of waste by their recycling activity are the most exposed to the risks produced by these wastes. As a consquence, the reduction of waste management vulnerability is carried out through the concentration of the vulnerability territories and very localized populations.
\end{abstract}

Key words: waste, vulnerability transfer, environmental inequalities, Lima

El fenómeno de metropolización es antiguo y bastante conocido en la América Latina (Dureau et al., 2005). Enormes aglomeraciones producen desechos en grandes cantidades, lo que representa un verdadero desafío para la gestión urbana, tanto en términos de recolección como de eliminación. A menudo la gestión de residuos no es una prioridad para las políticas urbanas, pese a su importante impacto sobre el medio ambiente urbano. La aglomeración de Lima/Callao, que se extiende sobre $1100 \mathrm{~km}^{2}$ y registra 8 millones de habitantes, produce cotidianamente 6420 toneladas de residuos municipales1, $14 \%$ de las cuales no reciben un tratamiento adecuado tal como lo define la legislación peruana, es decir no llegan a los rellenos sanitarios oficialmente habilitados para recibirlos.

La mayoría de las investigaciones sobre el tema de los residuos enfoca la gestión del servicio público, del medio ambiente urbano o de las técnicas de valorización de los residuos. Este texto se propone estudiar los residuos desde el ángulo de la vulnerabilidad de la población y del territorio. La vulnerabilidad remite a un conjunto de elementos que hacen de los residuos un riesgo para la sociedad

1 Son considerados residuos municipales los residuos producidos por las familias, los comercios, las instituciones públicas así como aquellos que provienen de la limpieza de parques y vías públicas. 
urbana, en términos no solo sanitarios y ambientales, sino también económicos y sociales. La exposición de los territorios y de la población a estos riesgos define la vulnerabilidad producida por los residuos. Este enfoque permite dar otra mirada al tema de los residuos sólidos urbanos.

La primera parte de este texto detallará el funcionamiento y los actores de la gestión de los residuos en Lima evidenciando los problemas planteados por la articulación entre los diferentes niveles político administrativos involucrados. En la segunda parte, la observación del circuito de los residuos en la ciudad permitirá evidenciar las lógicas territoriales, sociales y económicas, indispensables para la comprensión de su gestión. En esta segunda parte, el estudio de la vulnerabilidad urbana se basa en el seguimiento de los desplazamientos de residuos operados por el conjunto de actores urbanos, y más precisamente en las transferencias de riesgos que estos representan. En efecto, el desplazamiento de residuos genera transferencias de vulnerabilidad de algunos espacios hacia otros, de algunas poblaciones hacia otras.

\section{EL MANEJO DE LOS RESIDUOS EN LIMA/CALLAO}

\section{1. Una gestión segmentada}

\section{1. 1. Intervención de las instituciones nacionales}

En el Perú las políticas de gestión de residuos sólidos son definidas por diversas instituciones, sin que ninguna llegue a controlar al conjunto de la cadena. Este diagnóstico es una de las conclusiones del seminario «Perusan» sobre saneamiento2 en el Perú, realizado en noviembre de 2008 por el WSP (Water Sanitation ProgramPrograma de Saneamiento del Agua) del Banco Mundial. El ministerio de Salud, el ministerio de Vivienda y el nuevo ministerio del Ambiente, creado en abril de 2008, comparten las competencias en cuanto a las políticas de saneamiento, sin que ninguna de estas tres instituciones pueda tomar las medidas necesarias para efectuar un control global de la gestión de los residuos sólidos. En efecto, cada categoría de residuos responde a una legislación diferente.

El ministerio de Salud es la entidad responsable de la aplicación de la legislación técnica, sanitaria y ambiental relativa a los residuos sólidos, que atañe mayormente a las municipalidades (residuos domésticos, comerciales y limpieza pública) y a las industrias (residuos industriales). La Digesa (Dirección General de Salud Ambiental) es el órgano de este ministerio que efectúa los controles de los rellenos sanitarios, de los centros de tratamiento y de transferencia de los residuos, de los materiales y del personal. Es la que autoriza a las empresas a recolectar, transportar y tratar los residuos municipales (residuos domésticos, residuos comerciales no peligrosos y residuos provenientes de la limpieza de las vías públicas), así como los residuos

2 El término «saneamiento» comprende la gestión de las aguas residuales y de los residuos sólidos. 
industriales. Sin embargo, muchas empresas y municipalidades pasan por alto estos controles, administrando todo o parte de los residuos dentro de un circuito informal, totalmente imbricado en el circuito legal.

El ministerio de Vivienda es el encargado de definir los lugares de depósito de los residuos de la construcción, así como de controlar su correcto traslado por parte de las empresas. Menos problemáticos a nivel sanitario que los residuos municipales $u$ hospitalarios, estos generan sin embargo numerosos problemas en Lima (cf. parte 1. 2.). Estos dos ministerios han elaborado la Ley General de Residuos Sólidos3, que enmarca su gestión.

Para coordinar las acciones de las diferentes instituciones, un Plan Nacional de Gestión Integrada de Residuos Sólidos ha sido implementado por el Conam (Consejo Nacional del Ambiente), institución incorporada al ministerio del Ambiente en el momento de su creación en 2008. Luego de hacer un diagnóstico de la situación peruana, este documento fija los objetivos en cuanto al mejoramiento del servicio, las metodologías y las agendas asociadas, pero sin ofrecer recursos adicionales a los actores principales que son las municipalidades. Como en la mayoría de sus ámbitos, el ministerio del Ambiente tiene pocas prerrogativas normativas en la materia y solo elabora guías, orienta las políticas públicas, y a lo sumo propone incitaciones financieras, por ejemplo para la implementación de un relleno sanitario o el mejoramiento del sistema de colecta. En numerosos casos, desempeña un rol de intermediario entre las municipalidades y las instituciones externas proveedoras de fondos (ONG o instituciones internacionales).

Por último, el ministerio de la Producción, encargado de la industria y de la pesca, tiene prerrogativas sobre la gestión de los residuos industriales, sin lograr el control o la orientación de la misma.

\section{1. 2. Los gobiernos locales}

En la práctica, las políticas públicas en materia de gestión de residuos son implementadas por las municipalidades (Riofrío et al., 1994). La Ley General de Residuos Sólidos fija su rol. Las municipalidades actúan en dos niveles: provincial y distrital (una provincia comprende varios distritos). La municipalidad provincial tiene competencias específicas sobre toda la provincia, pero también tiene competencias de municipalidad distrital sobre el distrito central de cada provincia (ejemplo: el Cercado de Lima). Cada distrito posee su propia municipalidad.

La aglomeración de la capital peruana corresponde a la jurisdicción de dos municipalidades provinciales: la de Lima, la MML (Municipalidad Metropolitana de Lima) con una población de 7605742 habitantes4, y la del Callao, con una población de 876877 habitantes y en la que se encuentran el aeropuerto y el puerto de la aglomeración. Estos dos gobiernos locales tienen la responsabilidad

3 Ley n. ${ }^{\circ} 27314$ de 2000, y su decreto de aplicación DS n. ${ }^{\circ}$ 057-2004-PCM de 2004.

4 Esta referencia proviene del censo nacional XI de población del Instituto Nacional de Estadísticas e Informática (INEI), 2007. 
de la eliminación de los residuos, es decir de la gestión de los rellenos sanitarios. También tienen que velar para que todos los residuos producidos por la ciudad sean transferidos a estos últimos.

Las 475 municipalidades distritales de la aglomeración6, tienen por su parte la responsabilidad de la colecta y del transporte de los residuos, sin ninguna intervención o control de las municipalidades provinciales. Esta división de las tareas entre dos niveles político administrativos independientes, genera numerosas dificultades y explica por parte que el $14 \%$ de los residuos municipales no sean enviados a los únicos lugares oficialmente habilitados para recibirlos, es decir los cinco rellenos sanitarios de la aglomeración.

El hecho que las municipalidades provinciales desempeñen igualmente el rol de municipalidad distrital en su cercado, crea confusiones en los funcionarios, quienes a veces tienen que actuar a nivel provincial y a veces a nivel distrital. Cada distrito gozando de amplia independencia, incluso financiera, las provincias tienen muchas dificultades para coordinar las políticas sobre el conjunto de su jurisdicción. Existen grandes diferencias en la gestión de residuos según los distritos, cuyo presupuesto depende del nivel socioeconómico de sus habitantes. Además, la ausencia de una institución que tenga competencias político administrativas sobre todo el espacio urbano de Lima/Callao, complica la gestión global de los residuos. Todas las investigaciones sobre los servicios públicos muestran que estos son más eficaces cuando existe una gestión a escala metropolitana (Le Bris, 2002; Gouëset, 2002). A este marco institucional se adjunta un sistema paralelo de tratamiento y eliminación de los residuos: sistema informal, totalmente imbricado e indispensable para el funcionamiento de la aglomeración (cf. parte 1. 3.)

\section{2. Residuos y discriminación socioespacial}

\section{2. 1. Producción de residuos y niveles socioeconómicos de los distritos}

La producción de residuos municipales no está repartida igualmente en la aglomeración. La población más rica es la que produce más basura. Como lo muestra la figura $n .^{\circ} 1$, los distritos de Lima han sido clasificados en cinco categorías en función del nivel socioeconómico dominante de la población (NSE)8. El nivel A corresponde a la categoría más acomodada y el nivel E a la categoría más pobre.

La aglomeración se ha desarrollado en torno a los centros históricos de Lima y del Callao. Se trata de barrios socialmente mixtos, con muchos edificios antiguos y deteriorados. Este centro se ha extendido hasta conformar la ciudad moderna, en torno a los distritos de San Isidro y Miraflores. Los barrios residenciales de esta

\footnotetext{
5 Además de esta cifra, hay que añadir las dos municipalidades de provincia de Lima y Callao, que tienen competencias de municipalidades de distritos en su cercado, en sus centros.

6 La Provincia de Lima está dividida en 43 distritos, la del Callao en 6 distritos.

7 Esta referencia viene de la base de datos de la Municipalidad Metropolitana de Lima (MML), 2007.

8 Categorización efectuada por el instituto privado de sondeo IPSOS-APOYO.
} 
ciudad moderna, de clases acomodadas y medias, se extienden desde los distritos de La Punta hasta La Molina. Alrededor de ese conjunto central se articulan tres periferias populares, cuyos centros están consolidados hoy en día. Los distritos situados en los extremos de la aglomeración acogen a las poblaciones más desfavorecidas (Driant, 1991; Hidalgo, 1999; Joseph, 2005) (fig. 1).

Según las estimaciones, la cantidad de residuos producidos al día en la aglomeración Lima/Callao es de 6420 toneladas9, o sea un promedio de 278 kg/año/hab. Los distritos más acomodados, donde dominan las categorías A y B, son los distritos que producen la mayor cantidad de residuos municipales por habitante. En 2007,

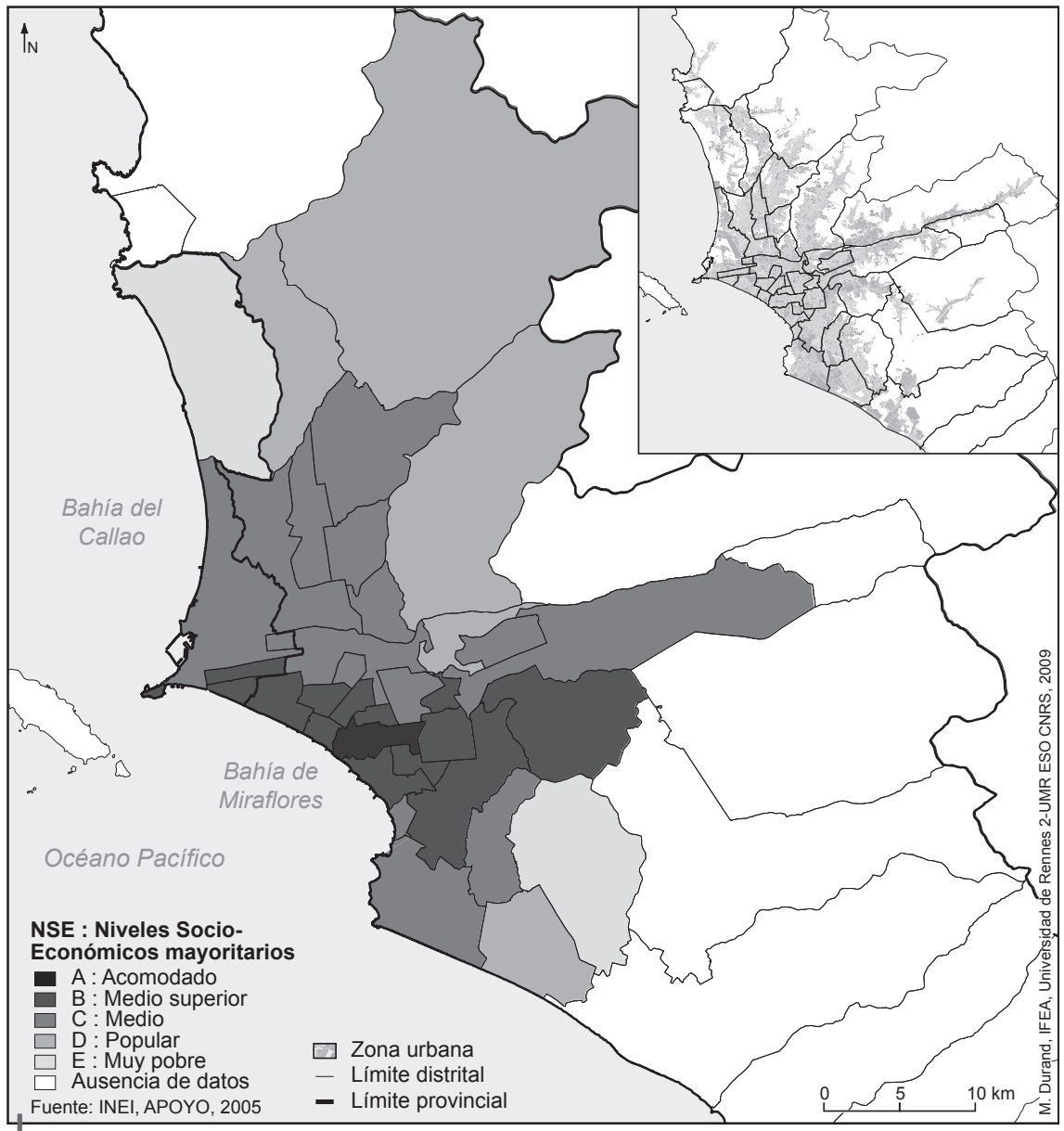

Figura 1 - Niveles socioeconómicos en Lima/Callao

9 Estimación efectuada anualmente por la Municipalidad Metropolitana de Lima y por la Municipalidad Provincial del Callao. 
los distritos de la ciudad moderna produjeron en su mayoría más de $300 \mathrm{~kg} / \mathrm{año} /$ hab. de residuos, como por ejemplo Pueblo Libre, $310 \mathrm{~kg}$, San Isidro, centro financiero de la ciudad, $569 \mathrm{~kg}$. Esta cifra se sitúa alrededor de $250 \mathrm{~kg} / \mathrm{año} / \mathrm{hab}$. en las periferias populares (274 kg en Independencia, $256 \mathrm{~kg}$ en El Agustino) descendiendo hasta $164 \mathrm{~kg}$ en Villa El Salvador (fig. 2).

Sin embargo, algunos distritos se alejan de la correlación que existe entre niveles socioeconómicos y cantidad de residuos, por producir muchos residuos pese a que su población sea de nivel socioeconómico medio o incluso pobre. Se trata de los distritos comerciales del centro (Cercado de Lima y La Victoria) o de las zonas industriales y comerciales de las periferias populares (San Martín de Porres, Comas, Santa Anita y Ate Vitarte). La gran producción de desechos en estos sectores proviene de las actividades comerciales, industriales y artesanales. Finalmente, en algunos distritos balnearios (Ancón y Punta Hermosa), los valores elevados se explican por el aflujo masivo de población en verano.

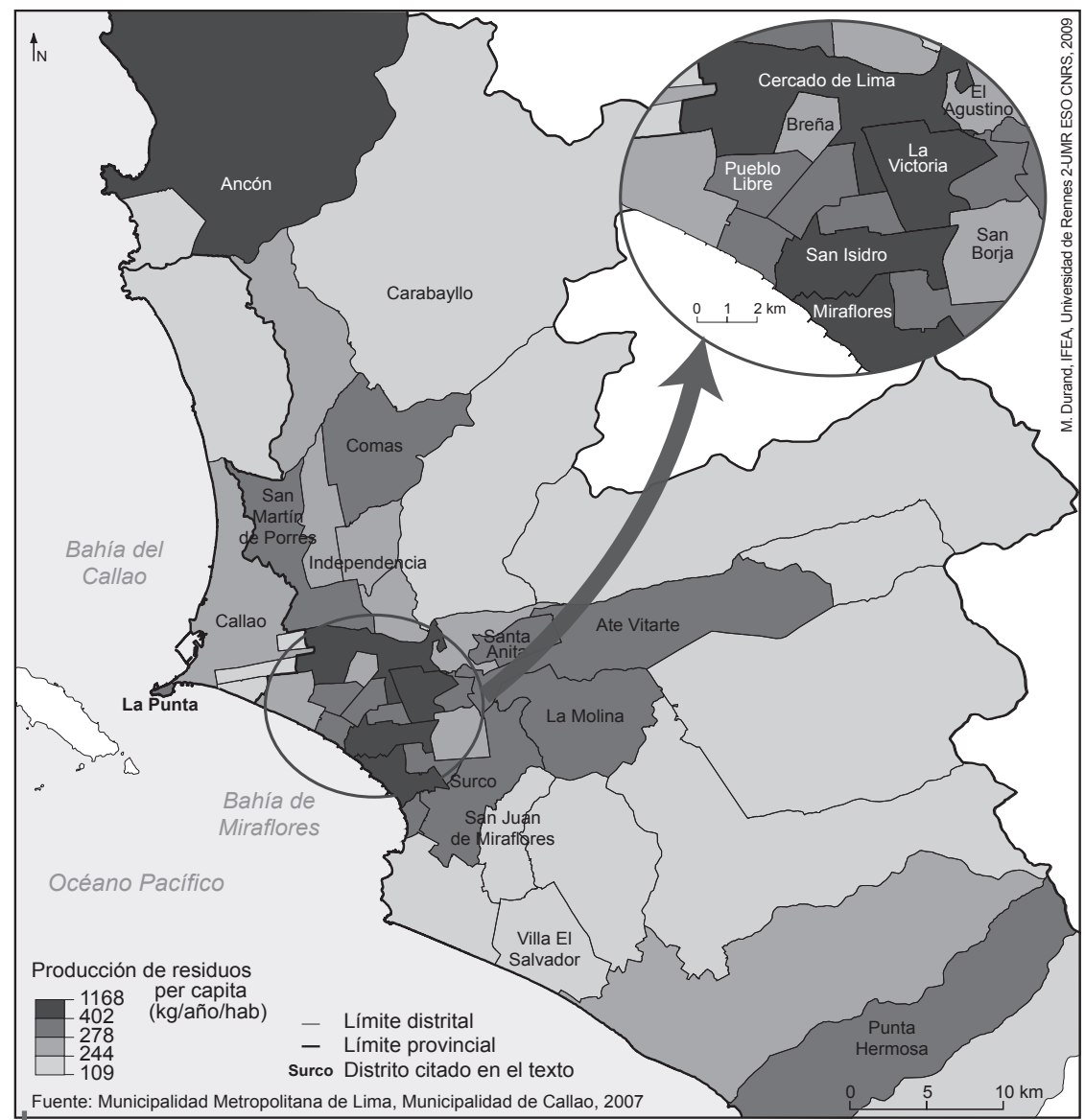

Figura 2 - Producción de residuos municipales per capita en Lima 


\section{2. 2. Colecta de los residuos municipales}

Las municipalidades de distritos tienen la responsabilidad de la colecta de los residuos municipales. La mayoría de estas municipalidades delegan este servicio público, al contratar una empresa privada para realizar este servicio.

Sin embargo, a menudo en las periferias populares, los distritos se encargan directamente del servicio. En este caso, es difícil manejar un servicio, en parte por la contratación de numerosos personales de colecta de basura, generalmente para responder a demandas clientelistas, lo que complica la tarea de colecta y de limpieza. Para simplificar la gestión, la mayoría de las municipalidades han optado por una delegación de servicio público. Esto no las exenta de otras dificultades, como la corrupción en la atribución de los contratos públicos por ejemplo. Así, el servicio de colecta de residuos domésticos está muy marcado por el clientelismo y la corrupción, ya sea público o privado. Con esto entramos en el complejo debate sobre las ventajas y los inconvenientes respectivos de la delegación de servicio público y de la gestión en administración directa. Algunas municipalidades han optado por un servicio mixto: en ciertas zonas el distrito se encarga directamente del servicio, en otras (generalmente donde existen dificultades de acceso), el servicio es operado por una empresa (distrito de Comas, por ejemplo).

En todos los casos, las dificultades radican esencialmente en la eliminación de los residuos y no en su colecta. En efecto, la limpieza de los espacios públicos (recojo de basura y limpieza de calles) es una tarea importante para los ediles locales. Junto con la seguridad y los espacios verdes, que también están a cargo de los distritos, se trata de los servicios más visibles prestados por las municipalidades distritales. La popularidad del alcalde dependerá en gran parte de su capacidad a ofrecer espacios públicos limpios y seguros. La tasa de residuos «controlados», es decir la proporción de los residuos recolectados y evacuados hacia centros de eliminación habilitados en relación con la estimación hecha por las municipalidades de la cantidad de residuos producidos, es relativamente buena en la aglomeración de Lima10 (fig. 3). Esta llega al 86 \%, o sea que la cantidad de residuos controlados es de 1857596 toneladas anuales.

Los distritos más acomodados son los que están en mejores condiciones de prestar un servicio de calidad. Por ende, los distritos como San Isidro (62 \% de los habitantes son de NSE A y $37 \%$ de NSE B), presentan una tasa de control de $98 \%$. Otros distritos periféricos como Puente Piedra o Villa El Salvador registran tasas de control de 86 \%. En estos dos distritos, la mayoría de la población se encuentra en los NSE D y E (94 y 73 \% respectivamente). Sin embargo, los distritos que tienen mayores dificultades para recolectar sus desechos son los distritos populares, inmediatamente periféricos al centro histórico o a la ciudad moderna. Por su

10 La tasa de residuos «controlados» es sensiblemente diferente de la tasa real de residuos «recolectados» en razón de la pérdida de algunos residuos colectados (cf. parte 1. 3.). Sin embargo, en la ausencia de cifras relativas a los residuos realmente colectados, el volumen de residuos controlados es el más cercano al volumen de residuos recolectados. En este capítulo, el término de «residuos controlados» se asimilará al de «residuos recolectados». 


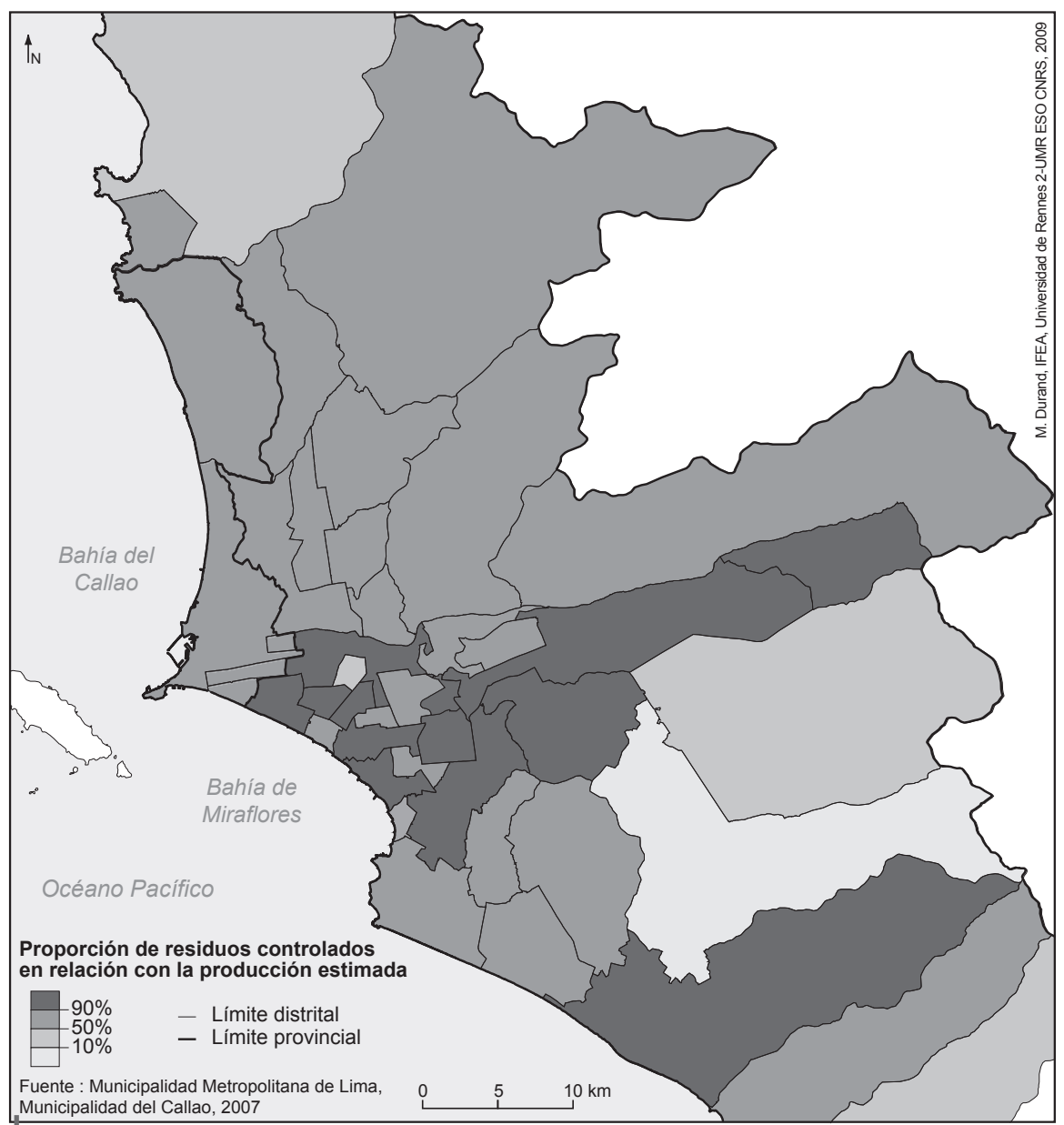
Municipalidad del Callao, 2007

Figura 3 - Control de los residuos municipales de Lima ${ }^{11}$

localización, estos distritos tienen una gran actividad comercial pero no perciben suficientes impuestos locales como para garantizar la limpieza de su territorio. Es el caso por ejemplo de San Juan de Miraflores y de La Victoria donde las tasas de control están de 72 y 80 \% respectivamente y la población mayoritariamente de clase media baja (NSE C)12.

Estas cifras no dejan entrever las grandes desigualdades en la calidad del servicio de recolección de basura que existen dentro de cada distrito. De manera general, los barrios consolidados (las «urbanizaciones»), disponen de un servicio diario

11 En cuanto al Callao, la información solo está disponible a escala de la provincia, no se detalla cada distrito.

12 El distrito pericentral de Breña está en la misma situación. Presenta una tasa de control de sus residuos excepcionalmente baja $(17 \%)$, en razón de la importante presencia de recicladores informales. 
de colecta de residuos domésticos ${ }^{13}$, mientras que los barrios populares, no consolidados (los «Asentamientos Humanos»), no tienen acceso a un servicio de igual calidad. A menudo la recolección no se hace sino interdiario, incluso una vez por semana, los vehículos no son compactadoras sino simples camiones baranda y el recorrido se limita a las avenidas principales. Por esta razón, estos barrios pagan arbitrios municipales menos elevados, aunque a veces no pagan nada.

\section{3. Tratamiento de los residuos}

El tratamiento de los residuos en Lima se hace a través de su disposición final en rellenos/botaderos (enterramiento) o a través del reciclaje (valorización). En ambos casos existe un circuito formal y un circuito informal.

\section{3. 1. Rellenos sanitarios y botaderos}

La cifra de 86 \% de los residuos controlados corresponde a los residuos registrados a la entrada de los cinco rellenos sanitarios de la ciudad en relación con la producción estimada de desechos. Estos rellenos sanitarios, bajo la responsabilidad de las dos municipales provinciales, están administrados por delegación de servicio público. El de Casren14 está operado por la empresa del mismo nombre, los de Zapallal y de Portillo Grande por la empresa Relima, y los de Modelo Callao y de Huaycoloro por la empresa Petramas. Estas mismas empresas operan el servicio de colecta de los residuos en muchas de las municipalidades. Petramas efectúa el servicio de colecta en seis municipalidades de la aglomeración, y Relima recolecta entre otros los residuos del cercado de Lima y de Miraflores. La empresa Casren por su parte, no se encarga de la recolección sino del reciclaje de algunos residuos sobre todo industriales, en su local en el centro de Lima. Las empresas encargadas de la colecta en un distrito evacuan los residuos hacia su propio relleno sanitario, aunque este pueda encontrarse muy alejado. Esto genera no solo costos de transporte superfluos sino también un riesgo de contaminación tanto mayor si el trayecto es largo.

La Ley General de Residuos Sólidos prohíbe la segregación y el reciclaje en los mismos rellenos sanitarios. El objetivo inicial era impedir que los segregadores informales trabajen directamente en los rellenos, por razones sanitarias y de seguridad (fig. 4). Sin embargo, actualmente estos rellenos funcionan bien y han establecido una serie de normas ambientales y sociales. Por ende, hoy en día, estos serían los lugares más adecuados para un reciclaje a gran escala, realizado en buenas condiciones sanitarias y sociales. En razón de esta prohibición, las

13 En el estudio de todos los servicios públicos en América Latina, actualmente es más necesario tomar en cuenta los criterios de calidad y de regularidad que los criterios de simple acceso.

14 Existe un litigio en torno a este relleno sanitario que opone a la empresa Casren con la Municipalidad de Ancón. Algunos acusan a otras empresas de estar detrás de este conflicto para recuperar la gestión de este relleno sanitario. 


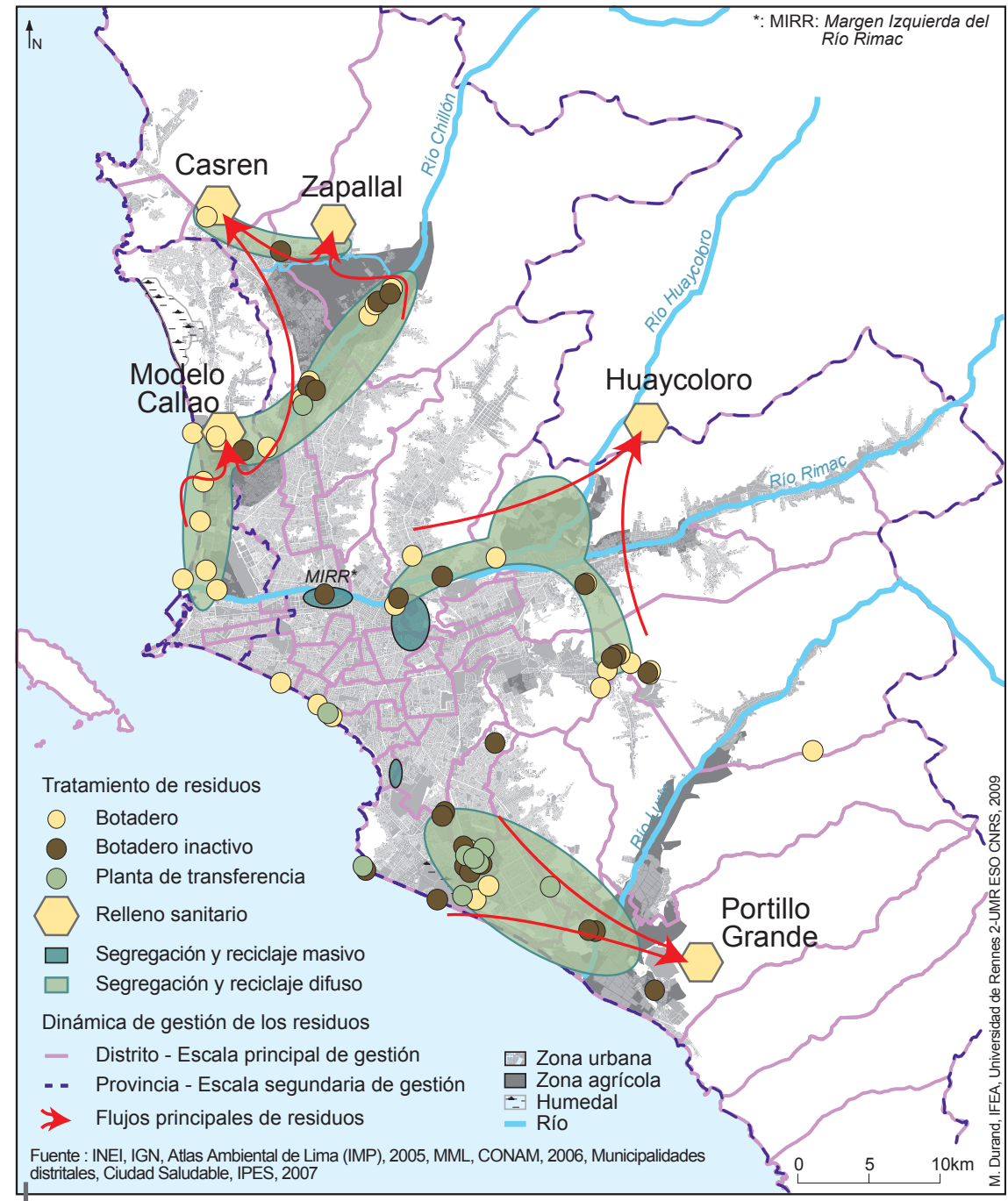

Figura 4 - Evacuación de los residuos sólidos en Lima

actividades de reciclaje se localizan al exterior de los rellenos sanitarios y las efectúan algunas empresas que tratan sobre todo residuos industriales, y también recicladores informales.

Por otro lado, los botaderos15 están localizados en la periferia urbana, generalmente cerca de los ríos, de los humedales o de la costa. Se ubican en el camino hacia los rellenos sanitarios, con el fin de interceptar los flujos de residuos municipales, es

15 En el vocabulario peruano la diferencia entre un «botadero» y un «relleno sanitario» se hace en el hecho de que el primero sea incontrolado e informal, al contrario del segundo. 
decir comprarlos antes que lleguen a ellos. A veces, estos botaderos 16 son simples vertederos que reciben los residuos de la construcción (escombros), a veces se trata de verdaderas empresas de reciclaje, organizadas y perennes. Los 23 botaderos activos registrados por la MML en 200617, han acumulado con el paso del tiempo $57060 \mathrm{~m}^{3}$ de residuos en una superficie de 29,2 ha. La parte norte de Lima recibe la mayoría de los residuos municipales, mientras el sur y el este reciben sobre todo escombros. Estos últimos representan el 78 \% del volumen total de residuos registrados en los botaderos activos del territorio de la provincia de Lima.

La diferencia entre los residuos controlados y los residuos efectivamente recolectados, resulta del hecho que una parte de los residuos recolectados por los camiones municipales, no terminan en los rellenos sanitarios sino en estos botaderos. El interés de los recolectores de basura radica en que venden sus residuos a los gerentes de los botaderos o a los recicladores. Gracias a esta compensación financiera, los recolectores de basura toleran un salario muy bajo. Los recicladores, por su parte, obtienen un beneficio de esta operación segregando, lavando y después revendiendo los productos reciclables (plásticos, metales, cartones). Los residuos restantes son enterrados, quemados, o evacuados hacia los ríos, los humedales o el océano. Este sistema es permitido por el dejar hacer de algunos funcionarios, ediles, y de empresas especializadas. Esta situación tiende a desaparecer pero sigue existiendo.

Por otro lado, algunas municipalidades o empresas poseen plantas de transferencia de residuos, es decir lugares de almacenamiento intermediarios entre la colecta y el relleno sanitario, que facilitan el transporte de los residuos hacia su lugar de disposición final. Generalmente en estas plantas se realiza un reciclaje informal.

\section{3. 2. El reciclaje}

El sistema de gestión de residuos permite su eliminación a través de un circuito paralelo de reciclaje informal, aun cuando el circuito formal esta fortaleciéndose. Los residuos oficialmente reciclados son principalmente residuos industriales, recolectados directamente por empresas de reciclaje especializadas contratadas por las industrias mismas. Algunas municipalidades también han implementado un reciclaje en la fuente, es decir la segregación de los residuos en casa de los habitantes. En todo caso, se trata de programas experimentales, que no benefician a la totalidad de los habitantes. El distrito de Surco es el más avanzado en la materia, pero los de Los Olivos o de Villa El Salvador también han implementado iniciativas similares.

En cuanto al resto del mercado del reciclaje, la imbricación es grande entre el circuito formal y el circuito informal. Existen aproximadamente 350 empresas que

\footnotetext{
16 Hay que diferenciar los «botaderos» de los «depósitos», simples amontonamientos de residuos domésticos, depositados por los vecinos quienes no tienen acceso al servicio de colecta de los residuos domésticos.

17 Este censo no toma en cuenta los botaderos ubicados en la Provincia del Callao.
} 
comercializan residuos en Lima (IPES, 2005), de las cuales 64 están registradas en la Digesa. Por consiguiente, el $20 \%$ de las empresas de reciclaje tienen existencia legal y constituyen el nivel intermedio del reciclaje, situado entre la colecta manual y la transformación industrial. Estas empresas, generalmente de mediano tamaño, centralizan los productos provenientes de los pequeños recicladores, los segregan, y efectúan una primera transformación (limpieza, trituración) antes de venderlos a industriales que harán con ellos productos reutilizables. En su mayoría estas empresas están ubicadas en las zonas pericentrales en donde se hace el reciclaje masivo, y en las zonas periféricas en donde se practica un reciclaje difuso (cf. fig. 4).

En torno a estas empresas se articulan cerca de 5000 «unidades económicas» (IPES, 2005), es decir micro empresas, generalmente familiares y siempre ilegales, que hacen el trabajo de recolección y de segregación de los desechos en el terreno, en la calle, en botaderos o en las empresas. Según el Movimiento Nacional de Recicladores del Perú y la ONG Ciudad Saludable, aproximadamente 25000 personas se dedican a esta actividad de manera permanente en la aglomeración de Lima/Callao.

\section{3. 3. Residuos peligrosos y residuos de la construcción}

Los residuos peligrosos y los residuos de la construcción escapan a las competencias municipales y responden a normas diferentes.

Por un lado, el tratamiento y la eliminación de los residuos hospitalarios son responsabilidad directa de los hospitales y del ministerio de Salud, y los residuos industriales de las empresas que los producen. Dos de los cinco rellenos sanitarios están habilitados para recibir los residuos peligrosos: el de Zapallal y el de Portillo Grande18. Los residuos hospitalarios representan un volumen anual de 11398 toneladas (MML, 2008), 53 \% de las cuales son enviadas hacia el relleno sanitario de Zapallal, y 47 \% a Portillo Grande. Además, algunos hospitales tratan directamente sus residuos, como el de Collique en Comas. La cantidad de residuos hospitalarios es muy pequeña en comparación con los 2,3 millones de toneladas de residuos municipales producidos anualmente, pero se trata de residuos particularmente peligrosos.

Es difícil estimar la cantidad de residuos industriales, por el carácter difuso y la falta de control sistemático de la producción de tales desechos. Las diferentes autoridades denuncian regularmente las empresas que no eliminan correctamente sus residuos. Por otro lado, existen algunas empresas especializadas en el tratamiento de los residuos industriales peligrosos. Por sufrir de una mala imagen de marca, esas son muy discretas sobre las cantidades que manipulan.

Finalmente, los residuos de la construcción son responsabilidad de cada empresario, de cada constructor. Sin vertedero oficial de escombros en la aglomeración (se está preparando una ley sobre el tema), estos terminan en los botaderos ubicados en los lugares abandonados de la ciudad: a lo largo de los ríos, en las playas, en

18 Existe un sexto relleno sanitario que trata algunos residuos peligrosos, al sur de Lima, en Chilca. 
la berma central de las avenidas, en las antiguas canteras o sobre los pendientes de los cerros de la ciudad. Presionado por ONG y municipalidades, el ministerio de Vivienda recién ha tomado conciencia de la necesidad urgente de elaborar normas y designar sitios para depositar estos residuos en buenas condiciones. Hoy en día, los escombros sirven para rellenar las playas de la bahía de Miraflores y prolongar así la vía expresa que las bordea, encima de los escombros.

\section{VULNERABILIDAD RELACIONADA CON LOS RESIDUOS}

La población es vulnerable cuando puede verse afectada por riesgos consecutivos a la producción y a la gestión de los residuos, que sean riesgos ambientales, sanitarios, morfológicos o socioeconómicos. Estos riesgos al afectar el territorio, lo hacen vulnerable y por eso mismo, hacen la población vulnerable.

La gestión de los residuos produce diferentes tipos de espacios, interpretables en términos de vulnerabilidad. En efecto, la gestión de los residuos consiste en organizar flujos para la evacuación y la eliminación de la basura en la ciudad. Los residuos representando riesgos, su traslado opera redistribuciones de riesgos y de vulnerabilidad. En consecuencia, los espacios pueden caracterizarse por sus funciones de producción, de recepción, de tratamiento y disposición de residuos, interpretables en términos de vulnerabilidad. Los flujos de residuos corresponden a transferencias de riesgo y de vulnerabilidad entre territorios y entre poblaciones. Se trata aquí de poner de relieve la dimensión territorial de la gestión de los residuos y los desplazamientos de vulnerabilidad que esta produce.

\section{1. Los riesgos vinculados a los residuos sólidos}

Los residuos son elementos físicamente desechados por la sociedad, debido a los riesgos que siempre han representado para la población. Estos riesgos son aprehensibles en términos ambientales (para el territorio y los recursos necesarios para la ciudad), sanitarios (directamente para las poblaciones), pero también en términos morfológicos (los residuos son fuente de destrucción de viviendas) y socioeconómicos (vinculados a los trabajadores en contacto con los residuos) (Durand, en prensa b).

\section{1. 1. Riesgos ambientales y sanitarios}

Los residuos producen un impacto sobre el medio ambiente urbano, sobre los ecosistemas, y más que nada sobre la salud pública. En una óptica de estudio de la vulnerabilidad de las poblaciones, el componente sanitario del ambiente llama particularmente la atención.

Los rellenos sanitarios, únicos lugares habilitados para enterrar los residuos, supuestamente no contaminan localmente (aun cuando este punto es discutido en Lima). Sin embargo, la proximidad de algunos rellenos con unos barrios, representa 
un riesgo sanitario para estas poblaciones, como por ejemplo, en Zapallal. Por esta razón la legislación impone una distancia mínima de 1000 metros entre un relleno sanitario y una zona residencial. Conviene recalcar el poco respecto de esta noma. Lo ejemplifica el barrio de Lomas de Carabayllo construido alrededor del relleno sanitario del Zapallal. Cerca de 50000 personas viven hoy en día a proximidad de este espacio que constituyó en otros tiempos una fuente directa de empleos. Los recicladores informales que trabajaban en el relleno sanitario hace 20 años se instalaron naturalmente al lado de su lugar de trabajo (Cesip, 2006; Cavagnoud, 2008). Cuando se aplicó la prohibición de reciclar en el relleno sanitario, estas poblaciones tuvieron que interceptar los residuos antes de su ingreso al relleno sanitario (comprándolos) y organizaron el reciclaje dentro de su propia casa. Una situación similar existe alrededor de los otros rellenos sanitarios de Lima/Callao.

Más allá del riesgo sanitario reforzado por la ocupación urbana en las cercanías de los rellenos y botaderos, el impacto sanitario de la actividad de reciclaje es importante. Esta actividad se realiza en los botaderos o en los barrios «especializados», generalmente construidos sobre antiguos botaderos como es el caso de la MIRR19 (Margen Izquierda del Río Rímac, D’Ercole \& Sierra, 2008; Robert y Sierra en este volumen: pp. 595-621). Al comienzo los rellenos sanitarios estaban alejados de las viviendas. Sin embargo, el crecimiento urbano y los empleos que ofrece el reciclaje atraen las poblaciones más pobres. Por ende, botaderos periféricos, como los que están situados a lo largo del río Chillón, están rodeados por viviendas cuya existencia es inferior a 10 años. Estas zonas periféricas conocen una evolución similar a la del pericentro de Lima en el transcurso de las últimas décadas. Hoy en día, en el barrio de la MIRR, el antiguo botadero está en parte enterrado abajo de la zona urbana, y en parte emergente en un montículo de tierra mezclada con basura. Las emanaciones regulares de gas y la contaminación del suelo producen un gran riesgo sanitario.

Por último, la concentración de la actividad informal de reciclaje en algunos barrios es un factor importante de riesgos sanitarios no solo para los mismos recicladores sino también para los vecinos, lo que provoca numerosos conflictos entre estas dos categorías de población. El límite de los distritos de La Victoria y de El Agustino, así como la MIRR, son los principales focos de reciclaje en Lima (6 000 recicladores trabajan en la MIRR según las organizaciones profesionales de recicladores).

El reciclaje produce riesgos ambientales como la contaminación del suelo, de las napas freáticas, de los ríos y del mar en razón del enterramiento de los residuos. El aire también se contamina por la segregación de residuos al aire libre o por residuos no reciclables que son quemados.

El riesgo sanitario es medible por la prevalencia importante de enfermedades de la piel, de infecciones gástricas o respiratorias alrededor de los botaderos. Así, en la zona 14 del distrito de Comas, que corresponde a las riberas del río Chillón, la tasa de enfermedades diarreicas agudas es de casi 4000 por 100000 habitantes20,

19 Barrio localizado sobre la figura 4.

20 Según los datos del Centro de Salud Laura Rodríguez Dulanto, responsable de esta zona. 
contra un promedio de un poco más de 2000 por 100000 habitantes en el conjunto del distrito. Como la mayoría de los barrios en donde se concentran las actividades asociadas a los residuos, la zona 14 no tiene acceso a la red de agua potable y de alcantarillado. El origen de estas infecciones no se limita entonces a la presencia de residuos. Este se sitúa en la calidad global del ambiente urbano, principalmente en materia de evacuación de aguas residuales, de la contaminación vehicular, industrial, etc. Sin embargo, los residuos sólidos y líquidos siguen siendo las principales fuentes de contaminación del suelo y de los recursos de agua en la ciudad de Lima (Grupo GEA, 2007; Durand, en prensa).

\section{1. 2. Riesgo morfológico}

El impacto morfológico de los residuos se puede ilustrar otra vez, comparando las riberas del río Chillón y los barrios de la MIRR. El botadero del Montón ha permitido rellenar las riberas del río Rímac. Antes era sinuoso y fluctuante, hoy el Rímac es un río estrecho y encajonado. Durante 50 años, el aporte constante de residuos municipales y de residuos de la construcción de la ciudad de Lima, ha rellenado estas tierras inundables transformándolas en terrenos urbanizables. Sin embargo, la inestabilidad de los suelos rellenados provoca regularmente el desplome o el agrietamiento de las construcciones, y tanto más por cuanto se trata de una zona sísmica. Así, todos los años, varias casas construidas al borde del río, caen literalmente en él (el desnivel es de unos 20 m).

La situación es similar en Comas y Carabayllo, a lo largo del río Chillón, en donde la población se acerca progresivamente a los botaderos. En este sector, la existencia de una de las últimas zonas agrícolas potencialmente urbanizables, aumenta la presión sobre los rellenos de residuos, inestables, que se encuentran a lo largo del río.

Por último, existe un riesgo importante de incendio ligado a la actividad de reciclaje informal. El almacenamiento de materiales inflamables en una situación de alta densidad urbana y de proximidad con las cocinas domésticas, favorece los incendios y su rápida propagación. En los barrios de la MIRR, una de las zonas en donde se concentra el mayor número de recicladores de Lima, las viviendas presentan una gran vulnerabilidad frente al riesgo de incendio a causa de los materiales con las que han sido construidas y de la calidad de las instalaciones eléctricas (Coopi, 2008).

\section{1. 3. Riesgo socioeconómico}

Por un lado, los residuos son una fuente de empleo para numerosas familias. Sin embargo, la informalidad, incluso la ilegalidad de la actividad, así como las condiciones de trabajo hacen que estos empleos sean muy vulnerables y precarios, sensibles a la evolución de los precios de las materias recicladas pero también a las políticas públicas de saneamiento. Además, en cualquier momento se puede ver afectado el estado de salud de los trabajadores de reciclaje impidiéndoles ejercer 
su actividad y privándolos de ingresos. Aquí se consume el capital humano a gran velocidad.

Por otro lado, la mala imagen que tienen estos trabajadores los marginaliza en el seno de la sociedad urbana. Los vecinos y el resto de la población se distancian y no quieren saber quién hace el reciclaje, quién trabaja para valorizar las basuras producidas por el conjunto de la sociedad. Esta marginalización social y geográfica hace altamente vulnerables a estos trabajadores ilegales así como a su familia. Esto se une con una vulnerabilidad frente al sistema judicial que puede, en cualquier momento, cerrar su actividad o por lo menos paralizarla durante algunos días. Las municipalidades, acompañadas por la Policía Nacional y la Fiscalía de la Nación, efectúan regularmente operaciones de sensibilización, incluso clausuran centros de reciclaje. En regla general, los recicladores, ya sea porque no tienen opción y deben continuar ejerciendo su actividad profesional o porque se trata de pequeñas empresas decididas a no interrumpir su negocio, reabren rápidamente en un lugar diferente. Además, la corrupción en todos los niveles administrativos hace que en muchos casos, la operación fracase.

\section{2. Espacios de gestión de residuos y vulnerabilidad}

Las investigaciones sobre la vulnerabilidad ligada a los riesgos naturales y antrópicos, desarrolladas por el IRD en Quito (D'Ercole \& Metzger, 2004), han demostrado la existencia de fenómenos de desplazamiento (transmisión y transferencia) de vulnerabilidad. Si los residuos generan riesgos, los flujos materiales de residuos operados por su gestión corresponden a transferencias de vulnerabilidad.

La aplicación de este enfoque a los residuos de Lima permite poner de relieve los diferentes tipos de espacios producidos por la gestión de los residuos y las lógicas territoriales en marcha en la difusión y la reducción de la vulnerabilidad. La lectura de la gestión de residuos mediante las transferencias de vulnerabilidad entre espacios y entre poblaciones permite aprehender globalmente la cadena funcional y espacial de la gestión de residuos, evidenciar los procesos de desigualdad social y ambiental y apuntar a los territorios que deben ser objeto de atención específica de las políticas públicas.

La figura 5 presenta este sistema teórico, y la figura 6 intenta una aplicación (relativamente general y sucinta en este artículo) a la aglomeración de Lima.

\section{2. 1. Espacios generadores de vulnerabilidad}

De manera global, los residuos son generadores de vulnerabilidad por el simple hecho que exponen a la población a riesgos sanitarios y ambientales, entre otros. Por esto, a mayor cantidad de residuos producidos por la población de un espacio, mayor generación de vulnerabilidad de este espacio. Cuando son recolectados correctamente, los residuos producidos no tienen necesariamente un impacto sobre el lugar mismo de su producción, pero tienen un impacto a una escala más amplia (una cuenca, una aglomeración). 
Por ende, la vulnerabilidad debida a la producción de residuos debe estar relativizada en función de la calidad del servicio público de colecta y de evacuación de los residuos (Metzger, 1996). En las municipalidades que no ofrecen un servicio de aseo muy eficaz21, el sector geográfico es considerado como generador de vulnerabilidad, porque una parte consecuente de estos residuos escapa al circuito oficial. Esta generación de vulnerabilidad es tanto más grande cuando los distritos producen muchos residuos22. Por ende, la calidad de la colecta combinada con la cantidad de residuos producidos, permite obtener una estimación de la generación de vulnerabilidad a escala de la ciudad.

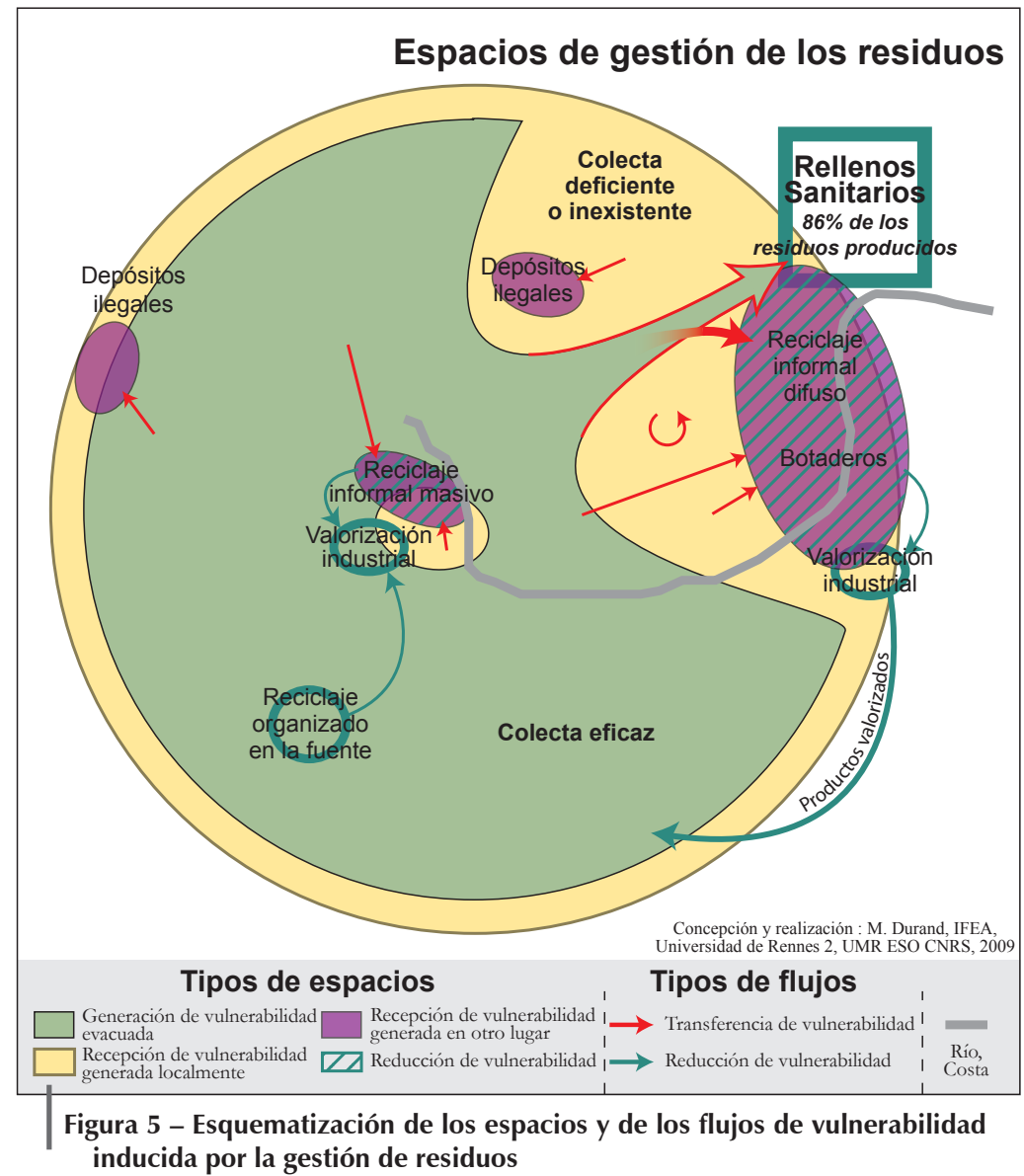

21 El umbral de 90 \% de residuos controlados ha sido fijado aquí de manera arbitraria como límite de un servicio muy eficaz. Sería necesario utilizar una discretización más fina, lo que no se ha hecho por afán de síntesis.

22 Aquí, el umbral de 278 kg/año/hab., es decir el promedio de producción per capita en Lima, ha sido escogido de manera arbitraria. 


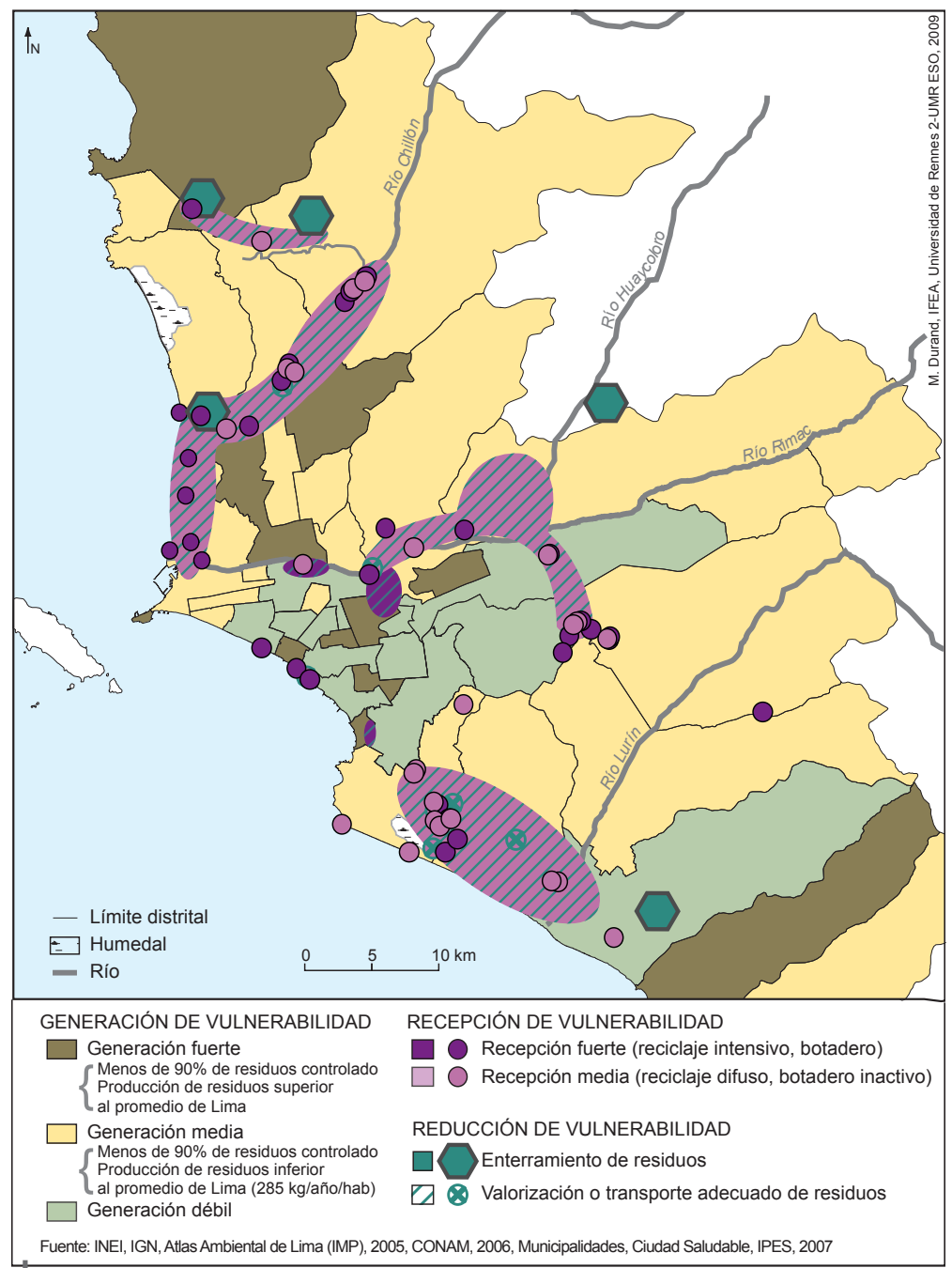

Fuente: INEI, IGN, Atlas Ambiental de Lima (IMP), 2005, CONAM, 2006, Municipalidades, Ciudad Saludable, IPES, 2007

Figura 6 - Espacios y flujos de vulnerabilidad inducida por la gestión de residuos en Lima

El servicio de recolección depende ampliamente del presupuesto municipal, en consecuencia existe cierta homogeneidad en la calidad del servicio de cada distrito. Sin embargo, dentro de ellos, los barrios consolidados tienen acceso a un mejor servicio que los barrios pobres. Una cartografía más fina permitiría representar este fenómeno.

\section{2. 2. Espacios receptores de vulnerabilidad}

La recepción de vulnerabilidad se hace a través de la recepción de residuos. Esta proviene de dos fenómenos. 
Primero, los residuos producidos a escala del conjunto de la aglomeración son evacuados, concentrados, segregados, y reciclados hacia algunos barrios en donde se realiza el reciclaje informal y en donde se ubican los botaderos activos. Entonces, la vulnerabilidad está concentrada, exacerbada dentro de barrios ya frágiles desde el punto de vista social, económico y ambiental. Estos barrios, en periferia urbana o en el pericentro inmediato, tienen pocas veces acceso a los servicios públicos urbanos, principalmente a la colecta de residuos municipales. Se trata de una situación paradójica: los lugares en donde se hace el tratamiento de los residuos del conjunto de la aglomeración no disponen de un buen servicio de recolección de basura.

La segunda fuente de recepción de residuos se hace a nivel local. Cuando el servicio de recolección es ineficaz o insuficiente, y que la parte de residuos controlados en relación con la estimación de los residuos producidos es débil, todo o parte de los residuos producidos permanecen en el lugar de producción y son reciclados, quemados o enterrados. Por ende, estas poblaciones se ven afectadas por su propia producción de residuos. Un escaso control deja pensar que parte de los residuos se queda en el mismo lugar, y genera una vulnerabilidad a nivel local. En consecuencia estos espacios son a la vez generadores de vulnerabilidad y receptores de esta misma vulnerabilidad que han producido.

\section{2. 3. Espacios reductores de vulnerabilidad}

La tercera categoría de espacios es aquella que permite reducir la vulnerabilidad del territorio en relación con la gestión de residuos. Son espacios que permiten tratar y valorizar los residuos, para limitar los riesgos ambientales y sanitarios. Los cinco rellenos sanitarios de Lima pueden ser considerados como espacios que permiten reducir la vulnerabilidad porque estos entierran los residuos para minimizar los impactos ambientales. Las condiciones de enterramiento, así como las condiciones de trabajo de los empleados no son perfectas. Sin embargo, son mejores que en la mayoría de los otros casos.

Por lo tanto, los espacios donde se hace reciclaje, en la medida en que contribuyen a la eliminación de residuos mediante su valorización, participan en la disminución de la vulnerabilidad a escala de la aglomeración. La situación es paradójica, porque en estos mismos lugares (localizados con color violeta en las figuras 5 y 6), la vulnerabilidad de la población es más elevada. Si bien la población local está fuertemente afectada, la actividad del reciclaje es benéfica a escala de la ciudad, del sistema urbano global. En efecto, esta actividad permite a la sociedad recuperar «materias primas secundarias» (Lacoste \& Chalmin, 2006), obtener una ventaja económica y ambiental, y a la par contribuir de manera formal o informal a la eliminación de los residuos. Todo esto se hace a costa de los profesionales de los residuos y a veces de los vecinos, expuestos a un gran riesgo sanitario y a un riesgo social de exclusión. Solamente a partir de la etapa de transformación industrial la transferencia de vulnerabilidades se convierte efectivamente en reducción de vulnerabilidad, gracias al resultado del producto reciclado: este es un impacto positivo para el sistema de gestión de residuos y 
para la sociedad urbana, es decir a escala global, a pesar del elevado costo pagado por los trabajadores en términos sanitarios, económicos, sociales y de seguridad a escala local. La situación actual de Lima tiende hacia el incremento de este tipo de espacios, aunque los riesgos ligados a los residuos siguen siendo numerosos. Es el caso, por ejemplo, de algunas fábricas formales de reciclaje de papel que arrojan al río Chillón sus aguas residuales. Esta contaminación por la actividad de reciclaje disminuye inmensamente el impacto positivo de la valorización de los residuos sólidos.

\section{3. Intereses del enfoque a través de la vulnerabilidad}

\section{3. 1. La transferencia de vulnerabilidad: una fuente de desigualdades socio- ambientales}

Por un lado, relacionar estos tres tipos de espacios permite evidenciar algunas lógicas territoriales. En la mayoría de los casos, los distritos que producen más residuos, es decir los que tienen comportamientos de consumo masivo, son los que realizan una buena colecta de los residuos. Se trata en gran parte de los distritos de la ciudad moderna, de la ciudad acomodada, tal como lo muestra el cruce de esta informacicón con la figura 1. Estos espacios son grandes productores de riesgos, pero no son vulnerables por la eficacia de los servicios municipales de aseo que evacuan estos riesgos. Además, en estos distritos se encuentran las experiencias de colecta de residuos reciclables en la fuente.

Por otro lado, es interesante la concordancia perfecta entre los espacios más vulnerables (los que reciben los residuos del resto de la ciudad) y los espacios que permiten reducir la vulnerabilidad de toda la aglomeración. Sin embargo, los botaderos y los barrios en donde se opera el reciclaje son casi los únicos lugares de Lima en donde se hace una valorización de los residuos, a pesar de que llevan el estigma de lugares insalubres, peligrosos, marginalizados. Así, las poblaciones que están más expuestas a los riesgos producidos por los residuos, son también las que permiten reducir la vulnerabilidad global del sistema, disminuyendo el impacto de los residuos sobre el ambiente urbano. Los otros lugares que permiten una valorización sin impactos sanitarios y sociales a nivel local son las empresas formales de reciclaje de residuos (localizadas dentro de las zonas de reciclaje informal) y las municipalidades que han implementado una colecta de los productos reciclables. La primera categoría trabaja principalmente con los residuos industriales, y la segunda no es todavía suficientemente significativa como para tener un impacto real a escala metropolitana.

La relación existente entre los espacios generadores y los espacios receptores de vulnerabilidad, caracteriza la transferencia de vulnerabilidad. Los residuos producidos en la mayoría de los barrios de la ciudad son evacuados, tratados y almacenados en otros barrios. Es decir que se transfiere la vulnerabilidad, y los riesgos producidos por los residuos hacia otros espacios, hacia otras poblaciones. Es una transferencia de vulnerabilidad de la casi totalidad de la aglomeración 
hacia los barrios más pobres. Esta transferencia es emblemática de la producción y del refuerzo de las desigualdades socio-ambientales: las poblaciones más desfavorecidas, más vulnerables socialmente, son igualmente aquellas que se ven más afectadas por la contaminación del ambiente (Laigle, 2005; Emilianoff, 2006). Además, al concentrar los residuos y la contaminación, esta transferencia la hace tanto más peligrosa.

\section{3. 2. Hacia una reducción de la vulnerabilidad}

El componente relativo a la reducción de la vulnerabilidad se refuerza cada vez más en el sentido en que globalmente, el sistema de gestión de residuos en Lima tiende a mejorarse, particularmente a través de la implementación de políticas públicas orientadas hacia la gestión del ambiente urbano.

Así, algunas municipalidades llevan a cabo políticas dinámicas para mejorar la gestión de residuos. Los Pigars (Planes Integrales de Gestión Ambiental de Residuos Sólidos) implementados por las provincias deben coordinar las acciones de diferentes actores e identificar los objetivos a alcanzar. Aunque no habilitados para realizar estos documentos, numerosos distritos los elaboran. Los SLGA (Sistemas Locales de Gestión Ambiental) apoyados y aprobados por el ministerio del Ambiente se encaminan a una gestión integral e integrada del medio ambiente, articulando a todos los actores dentro de mecanismos de toma de decisión institucional compartida y mecanismos de participación ciudadana. En la mayoría de los casos, las instituciones implementadas localmente por estos SLGA consideran los residuos sólidos como un objeto de acción prioritaria. Finalmente se espera que los embriones de organismos de cuencas (como el Grupo Técnico Estratégico de la Cuenca del río Chillón, apoyado por la ONG Alternativa), tomen más importancia en las decisiones y en las acciones de lucha contra la vulnerabilidad ligada al conjunto de residuos (A. Sierra, J. Robert, M. Durand y C. Abad en este volumen, pp. 777-797).

Estas diferentes políticas interinstitucionales son la consecuencia directa de la falta de gestión a escala metropolitana. La compleja división político administrativa, la ausencia de institución apta para actuar a escala de la aglomeración, la falta de peso de la Municipalidad de Lima hacen que el tratamiento de los residuos sea problemático. Además, le falta cohesión socio territorial a la ciudad de Lima/ Callao. Los distritos tienen competencia para elaborar sus propias políticas de manera totalmente independiente, cada uno actuando en función de sus recursos financieros y de intereses locales. Por último, la falta de concertación entre las diferentes políticas y la muy alta compartimentación entre las políticas denominadas «ambientales» y las políticas «urbanas» no contribuyen a la reducción de las vulnerabilidades asociadas a los residuos. 


\section{CONCLUSIÓN}

La gestión de los residuos es realizada por las 49 municipalidades distritales y provinciales de la aglomeración de Lima/Callao, lo que genera dificultades de gestión. $14 \%$ de los residuos producidos no son eliminados de la manera señalada por la legislación peruana. El reciclaje, que permite tratar, eliminar y valorizar los residuos, es en gran parte informal y es realizado en malas condiciones sanitarias y de seguridad por las poblaciones más desfavorecidas y más vulnerables.

Estas dificultades generan riesgos a escala de la aglomeración. Estos riesgos se ven atenuados por la actividad del reciclaje efectuada por numerosos trabajadores, numerosas pequeñas empresas informales y esto en ausencia de cualquier reconocimiento de su rol efectivo en la eliminación y el tratamiento de los residuos. El reciclaje permite reducir la vulnerabilidad global de la aglomeración relacionada con los residuos, porque los valoriza y disminuye los impactos sobre el ambiente urbano. Sin embargo, esta disminución de vulnerabilidad a escala global se hace a través de la concentración de la vulnerabilidad a escala local. El impacto sanitario y ambiental de los residuos puede ser disminuido en la aglomeración de Lima, mediante la transferencia y la concentración de la vulnerabilidad que estos producen, en espacios en donde estos residuos son eliminados por reciclaje.

En resumidas cuentas, la población urbana, que produce basura y tiene acceso a un servicio de recolección eficaz transfiere la vulnerabilidad que genera hacia los barrios y las poblaciones más pobres. Estas transferencias de vulnerabilidad refuerzan las desigualdades socio ambientales pero permiten al mismo tiempo la reducción de la vulnerabilidad del sistema urbano. Las políticas públicas, al focalizarse sobre la limpieza de los espacios públicos, han prestado menor atención a la fase de tratamiento y de eliminación de los residuos recolectados, favoreciendo así la transferencia de vulnerabilidad hacia los barrios y las poblaciones más desfavorecidos.

\section{Referencias citadas}

CAVAGNOUD, R., 2008 - Les adolescents travailleurs de Lima entre école et stratégies de survie, 373 pp.; París: IHEAL. Tesis de doctorado.

CESIP, 2006 - Dejando el basural, una experiencia con niñas, niños y adolescentes que trabajan en el reciclaje de la basura en las Lomas de Carabayllo, 112 pp.; Lima: Cesip.

COOPI, 2008 - Estudio de identificación de zonas de peligro y vulnerabilidad en seis asentamientos humanos de Lima y El Agustino, 84 pp.; Lima: Coopi, IRD, MML, Municipalidad de El Agustino.

D'ERCOLE, R. \& METZGER, P., 2004 - La vulnerabilidad del Distrito Metropolitano de Quito, 496 pp.; Quito: MDMQ, IRD. 
D'ERCOLE, R. \& SIERRA, A., 2008 - Enjeux urbains contradictoires et vulnérabilité accrue dans un espace marginal péricentral : la rive gauche du Rimac à Lima (Pérou). Autrepart, 45: 105-122; París: IRD.

DRIANT, J.-C., 1991 - Las barriadas de Lima, 231 pp.; Lima: IFEA, Desco.

DURAND, M., en prensa a - Inégalités écologiques et eaux usées à Lima. In: L'eau mondialisée (G. Schneier-Madanes, ed.); París: La Découverte.

DURAND, M., en prensa b - Los residuos líquidos y sólidos de Lima, desigualdades sociales y ambientales. In: Modelos de gestión del agua en los Andes (F. Poupeau \& C. González, eds.); Lima: IFEA, PIEB, Embajada de Francia en Bolivia.

DUREAU, F., GOUËSET, V., MESCLIER, É., 2005 - Géographie de l'Amérique Latine, 374 pp.; Rennes: PUR.

GOUËSET, V., 2002 - Villes, société et action publique en Amérique latine, Étude de géographie comparée, 257 pp.; Rennes: Université de Rennes 2. Habilitación a dirigir investigaciones Vol. 3.

EMILIANOFF, C., 2006 - Connaître ou reconnaître les inégalités environnementales ? Travaux et documents ESO, n. ${ }^{\circ}$ 25: 35-43; Rennes: UMR ESO CNRS.

GRUPO GEA, CONAM, 2007 - Perspectivas del medio ambiente urbano: Geo Lima y Callao, 201 pp.; Lima: Conam.

HIDALGO, S., 1999 - Cono norte de Lima metropolitana, 216 pp.; Lima: ONG Alternativa.

IMP, 2005 - Atlas ambiental de Lima metropolitana, 155 pp.; Lima: Muncipalidad Metropolitana de Lima.

IPES, MML, 2005 - Estudio del mercado de reciclaje para Lima Metropolitana, 145 pp.; Lima: MML.

JOSEPH, J., 2005 - La ciudad, la crisis y las salidas, 277 pp.; Lima: ONG Alternativa, UNMSM.

LACOSTE, E. \& CHALMIN, P., 2006 - Du rare à l'infini, panorama mondial des déchets, 253 pp.; París: Economica.

LAIGLE, L., 2005 - Inégalités écologiques : un nouvel enjeu pour les politiques d'urbanisme? In: Inégalités environnementales et sociales : I'environnement, facteurs de cohésion urbaines ? (Institut d'Urbanisme de Paris, ed.): 16 pp.; París: IUP, Université de Paris XII.

LE BRIS, E., 2002 - Inscrire la question de l'assainissement et des déchets dans une problématique urbaine, 17 pp.; París: PSEAU, PDM. Programa « Gestion durable des déchets et de l'assainissement urbains ».

METZGER, P., 1996 - El medio ambiente urbano en Quito, 179 pp.; Quito: MDMQ, IRD.

RIOFRIO, G., OLIVERA, L. \& CALLIRGOS, J.C., 1994 - iBasura o desechos? El destino de lo que botamos en Lima, 165 pp.; Lima: Desco. 